\title{
Differences in Platelet Glycoprotein Expression During Menstruation Cycle and Ovulatory Phase
}

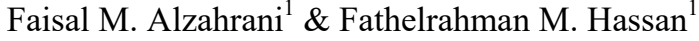 \\ ${ }^{1}$ Department of Clinical Laboratory Science, College of Applied Medical Science, Imam Abdulrahman Bin Faisal \\ University, Dammam, Saudi Arabia \\ Correspondence: Faisal M. Alzahrani, Department of Clinical Laboratory Sciences, College of Applied Medical \\ Sciences, Imam Abdulrahman Bin Faisal University, P.O. Box: 1982, Dammam 31144, Saudi Arabia. Tel: \\ 966-56-665-5776. E-mail: fmzahrani@iau.edu.sa
}

\author{
Received: November 4, 2018 Accepted: February 15, 2019 Online Published: February 25, 2019 \\ doi:10.5539/gjhs.v11n3p83 URL: https://doi.org/10.5539/gjhs.v11n3p83
}

\begin{abstract}
Introduction: The variations in the physiological properties of female platelets during menstrual cycle phases, pregnancy and postmenopausal women to interactions with platelet CD49b, CD42b, CD41a and CD61 expression glycoprotein receptors were not well understood. Therefore, the aim of the present study was to evaluate the expression of these glycoprotein receptors during menstruation and ovulatory phase of menstrual cycle in reproductive age women.

Methods: It is across section study including 44 healthy young non-hormonal contraceptives taking women aged between 19-44 years to determine the effect of estrogen on the expression level of platelet glycoprotein receptors (GPIb, GPIIa, GPIIb and GPIIIa) in its resting state in women in reproductive age.

Results: No significant difference in the expression of CD42b, CD41a and CD61 between menstruation and ovulatory phases in resting platelets in all subjects. However, this study showed a significant difference in CD49b expression in none-Arab ethnic subjects compared to Arab women.

Conclusion and Recommendations: This study suggested $\mathrm{CD} 49 \mathrm{~b}$ glycoprotein receptor used to be the commonly expression on the surface of platelet at some stage in menstruation and ovulatory segment of menstrual cycle in reproductive age women in turn extended platelet activity. Further studies including large number of subjects, platelet integrin gene polymorphisms and progesterone factors changes in platelet clotting associated to menstrual cycle should be conducted.
\end{abstract}

Keywords: hemostasis, platelets, glycoprotein, estrogen, menstruation, ovulatory phase

\section{Introduction}

Platelet plasma membrane supports more than 50 categories of receptors. These heterodimeric receptors support platelet adhesion and aggregation in the process of hemostasis. In case of blood vessel wall injury, platelets are recruited to the site of vascular injury where the action of glycoprotein (GP) receptors take place due to exposure of subendothelial matrix which contains ligands for these receptors that includes collagen (Kiefel et al., 1995). Platelet aggregation activity is higher in females compared with males. The association between the phase of the menstrual cycle and platelet activity appears to vary with the type of agonist, but platelet aggregation is consistently lowest in the mid-luteal phase irrespective of the agonist used (Nir et al., 2010). Several physiologic properties of platelets from women have been shown to vary with the phase of the menstrual cycle. We have found that platelets from women bound more fibrinogen during the luteal phase (defined as 14 or fewer days from the onset of the next menstrual cycle, or the second half of the menstrual cycle) than during the follicular, suggesting a hormonal regulation of glycoprotein (GP) IIb-IIIa activation (Faraday et al., 1997). The number of $\alpha 2$-adrenergic receptors has been shown to peak at the onset of menses and to drop to $74 \%$ to $79 \%$ of that value during the middle of the cycle. Studies (Jones et al., 1983; Tarantino et al., 1994) suggest estrogen and/or progesterone regulate platelet activation and function. Estrogen- and androgen-responsive genes (Chen \& Mehta, 1996; Gopal et al., 2000). There are controversies between the differences in platelets receptors expression between menstrual cycle phases during pregnancy or with hormone replacement therapy (HRT), but the exact effects are still not well understood. In the present study; we aimed to evaluate the expression of these CD Markers: CD42b; GPIb alpha, 
CD41 and CD61; GP IIb/IIIa and CD49b; GP Ia/IIa receptors during menstruation and ovulatory phase of menstrual cycle in women at reproductive age.

\section{Patients and Methods}

\subsection{Study Design \& Subjects}

This is a cross-sectional study conducted at Imam Abdulrhamn Bin Faisal University and King Fahad Hospital University /Saudi Arabia from May 2014 to January 2016; to determine the effect of estrogen on the expression level of platelet glycoprotein receptors (GPIb, GPIIa, GPIIb and GPIIIa) in its resting state in women in reproductive age. The study population consisted of 44 healthy young non-hormonal contraceptives taking women aged between 19-44 years old subdivided into two groups; Arab and none-Arab ethnic women.

\subsection{Data Collection}

The study was approved by the institutional review board (IRB) of the university (IRB-2014-04-282). Survey questionnaires were designed and distributed in Arabic and English. The survey included questions about demographic information, menstrual cycle status, physical and health status that could interfere with platelet reactivity or affect estrogen level. All subjects who fulfill the criteria of the study requirements gave their written informed consent to participate in the study. An informed consent was obtained from the patients, this informed consent procedure was conducted after the patient were interviewed and it was held about their participation, the purpose, and the risks related to the study.

\subsection{The Inclusion Criteria}

All women with a regular ovarian cycle, normal platelet function, without any intake of medications or other drugs that interfere, non-smoking, non-pregnant.

\subsection{Exclusion Criteria}

The exclusion criteria were all women with a family history of thromboembolic or bleeding disorders, high blood pressure, abnormal lipid profile, liver or renal disease, endocrinal and gynecological disorders, chronic diseases, hemoglobinopathies (sickle cell anemia disease, thalassemia or other), allergic conditions, presence of infection at the time of sampling, subjects with diabetes or performing regular strenuous exercise (Feuring et al., 2002; Rosin et al., 2006; Malipatil \& Patil, 2013).

\subsection{Measurements}

Quantitative analysis of Estrogen was done using citrated blood samples; the level was assessed by ARCHITECT I-optical system. The principle of quantitative determination was based on Chemiluminescent Microparticle Immunoassay (CMIA).

Flow cytometer was used for assessment of platelet glycoprotein receptors; Platelet Rich Plasma (PRP) was separated from citrated whole blood for determination of platelet glycoprotein receptors expression. Resting platelets were stained directly with different conjugated monoclonal antibodies: fluorescein isothiocyanate (FITC) Mouse Anti-Human CD49b, FITC Mouse Anti-Human CD42b, phycoerythrin (PE) Mouse Anti-Human CD41a and PE Mouse Anti-Human CD61. Appropriate isotype controls (FITC Mouse IgG1 ${ }_{k}$ Isotype Control and PE Mouse IgG1 $1_{\mathrm{k}}$ Isotype Control) were used to confirm the specificity of primary antibody binding and to roll out non-specific Fc receptor binding or other cellular protein interactions. After incubation, EDTA-PBS buffer was added to all tubes to remove unbound antibodies. The supernatant was decanted, and the platelets were suspended in $1 \%$ BD CellFIX $^{\mathrm{TM}}$ then analyzed by FACS Caliber.

Statistical analysis was carried out using SPSS version 20 and Microsoft Office Excel 2010. 10000 events were acquired for each sample in evaluation of platelets glycoprotein receptors. Dot plots and quadrant were used to calculate the median fluorescent intensity (MFI) of CD markers. The variation in glycoprotein receptors expression during menstrual cycle phases was determined as mean and standard deviation (SD). The $p$-values were determined for any difference in the expression of glycoprotein receptors, where a $p$-value $\leq 0.05$ was considered statistically significant. Calculations were performed using the SPSS version 16 . Paired $t$-tests were applied to evaluate the result in menstruation and ovulatory phase. Mean \pm standard error (SE) of the mean were used to plot the data.

\section{Results}

Forty-four (44) healthy females were recruited for evaluation of platelet glycoprotein receptors expression in resting state during different menstrual cycle phases. 


\subsection{CD49b Expression}

Variation in the $\mathrm{CD} 49 \mathrm{~b}$ expression during menstrual cycle phases was determined. A lack of significant difference of $\mathrm{CD} 49 \mathrm{~b}$ was exhibited between menstruation and ovulatory phase in resting platelets (mean $\pm \mathrm{SD}=40.65 \pm 8.83$ and $40.96 \pm 8.28$, respectively, $p=0.79$ ). Additionally, there was an absence of a significant difference in CD $49 \mathrm{~b}$ among Arab females (mean $\pm \mathrm{SD}=40.87 \pm 9.01$ and $40.18 \pm 7.96$, during menstruation and ovulatory phase; respectively, $p=0.65$ ). There was, however, significant difference in the expression of CD $49 \mathrm{~b}$ in none-Arab ethnic female (mean $\pm \mathrm{SD}$ during menstruation and ovulatory phase $=40.08 \pm 8.63$ and $43.06 \pm 9.08$ respectively, $p=0.03$ ) (Figure 1).

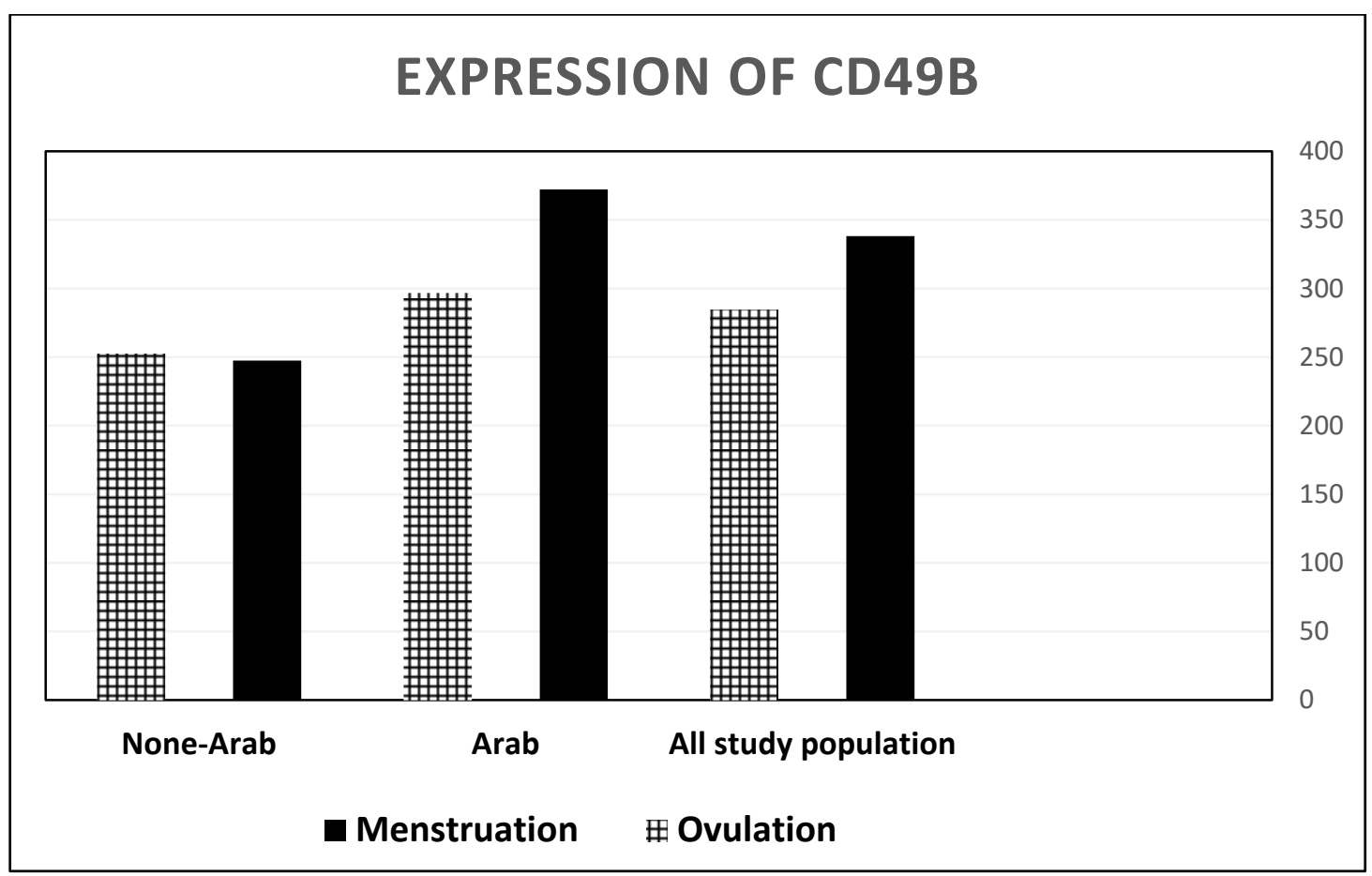

Figure 1. Expression of platelet CD49b during menstruation and ovulation; in all study population $(p=0.79)$, Arab $(p=0.65)$ and none-Arab females $(p=0.03)$. The MFI values presented as mean + S.E.

\subsection{CD42b Expression}

This study showed that there were no significant differences in platelet CD42b expression in resting state during menstrual cycle phases. The results were represented as mean \pm SD of MFI during menstruation and ovulatory phase ( $152.71 \pm 31.54$ and $146.02 \pm 44.75$; respectively, $p=0.37)$. Additionally, there were no differences in $\mathrm{CD} 42 \mathrm{~b}$ expression during menstruation and ovulatory phase neither in Arab (mean $\pm \mathrm{SD}=159.09 \pm 31.80$ and $149.25 \pm 49.77, p=0.32)$ nor none-Arab females (mean $\pm \mathrm{SD}=135.69 \pm 24.60$ and $137.40 \pm 27.09, p=0.85)$ (Figure 2). 


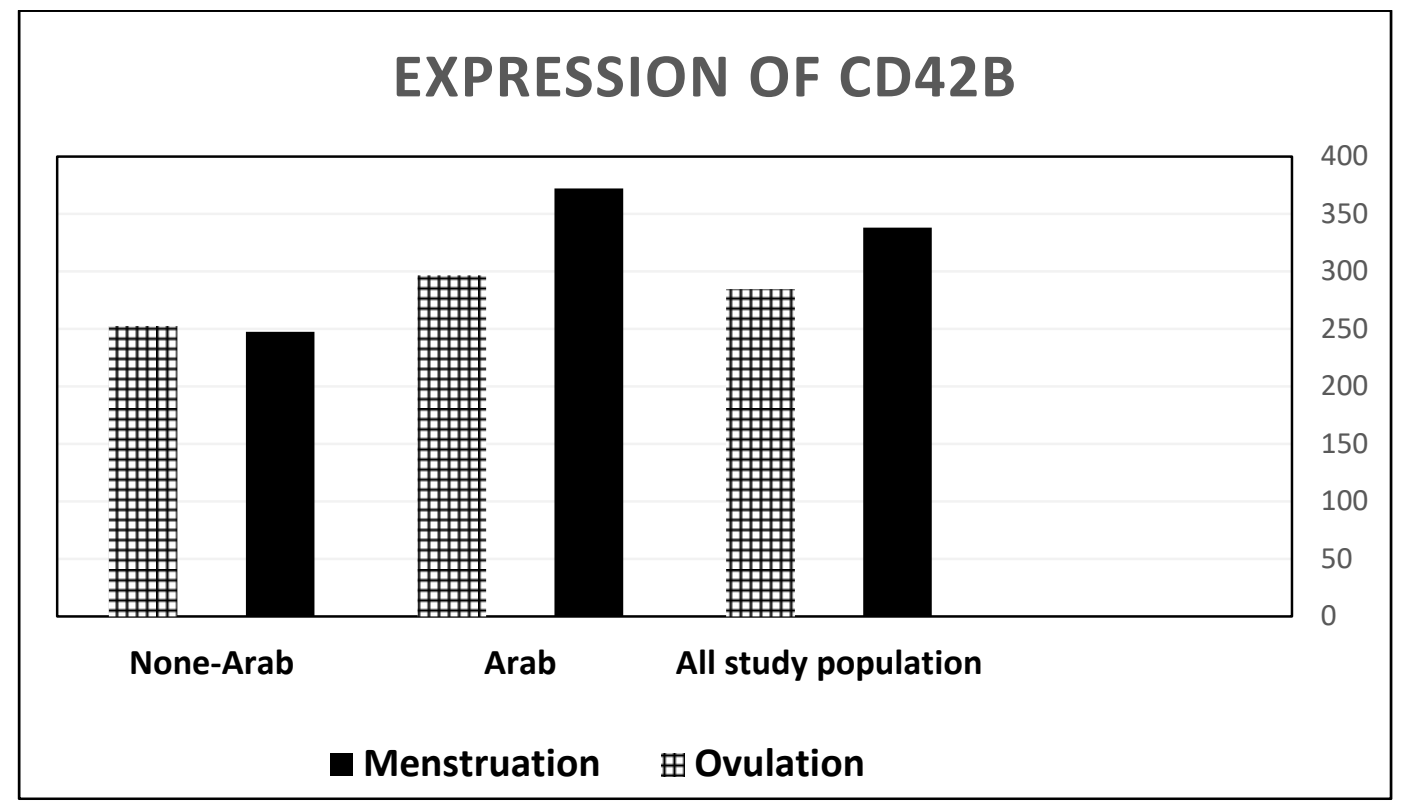

Figure 2. Expression of platelet CD42b during menstruation and ovulatory phase; in all study population ( $p=0.37)$, Arab $(p=0.32)$ and none-Arab females $(p=0.85)$. The MFI values presented as mean+S.E.

\subsection{CD41a Expression}

The expression of platelet CD41a was assessed for study subjects during menstruation and ovulatory phase in resting state. The MFI values with mean $\pm \mathrm{SD}=64.97 \pm 61.79$ and $47.35 \pm 6.76, p=0.06$. There were no significant differences in CD41a expression between menstruation and ovulatory phase. The absence of significant differences was also seen among Arab (mean $\pm \mathrm{SD}=72.32 \pm 71.27$ and $48.46 \pm 6.79, p=0.07$ ) and none-Arab females (mean $\pm \mathrm{SD}=45.36 \pm 5.94$ and $44.39 \pm 5.97, p=0.65$ ) (Figure 3).

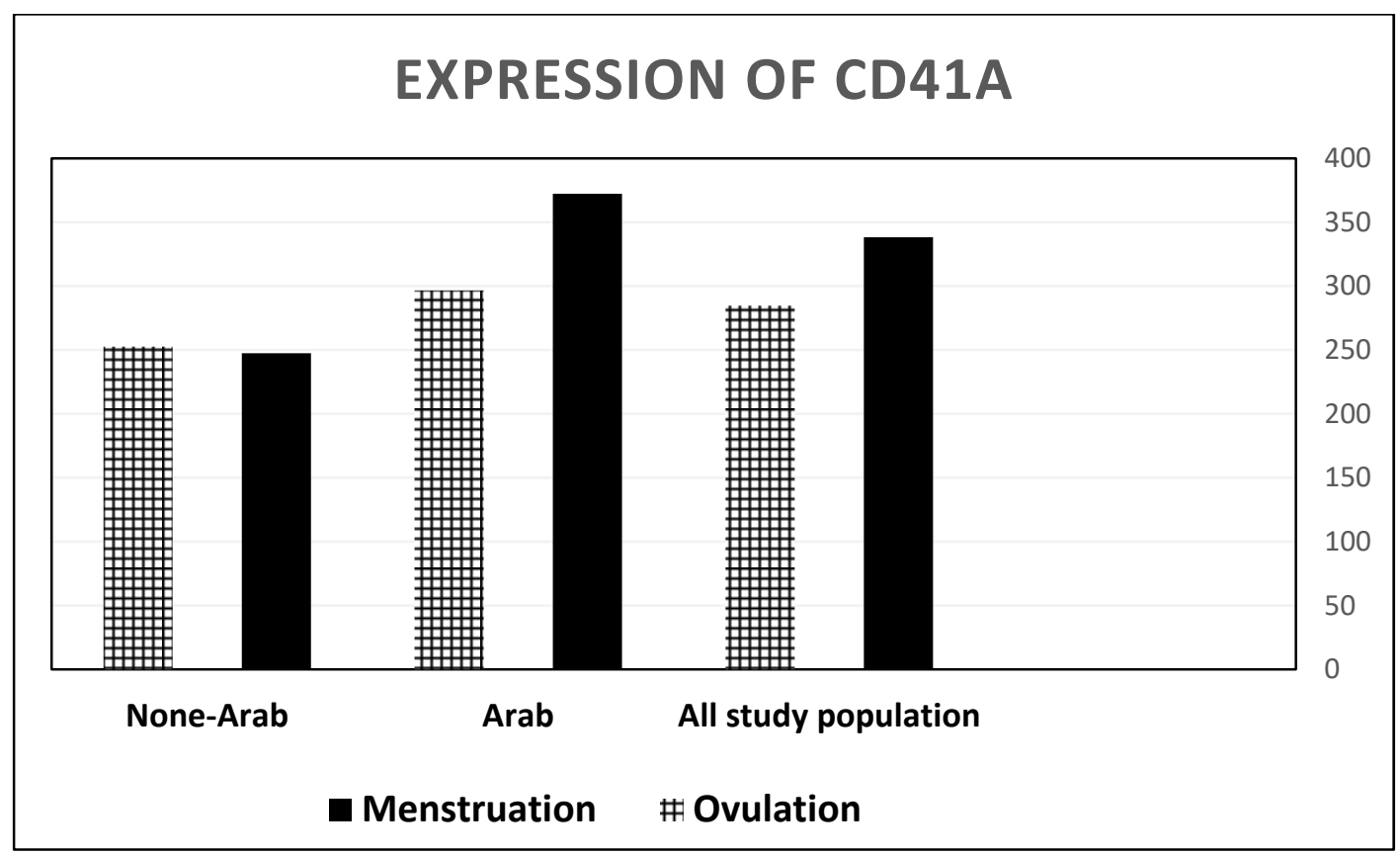

Figure 3. Expression of platelet CD41a during menstruation and ovulation; in all study population $(p=0.06)$, Arab $(p=0.07)$ and none-Arab females $(p=0.65)$. The MFI values presented as mean+S.E. 


\subsection{CD61 Expression}

This study data showed that there were no significant differences in platelet CD61 expression in resting state during menstruation and ovulatory phase. The results were represented as mean $\pm \mathrm{SD}$ of MFI during menstruation and ovulatory phase $=338.19 \pm 196.93$ and $284.62 \pm 71.10$, respectively, $p=0.09$ ). Furthermore, absence of significant differences was also seen during menstruation and ovulatory phase in Arab (mean $\pm \mathrm{SD}=372.21 \pm$ 215.72 and $296.64 \pm 72.57$, respectively, $p=0.07$ ) and none-Arab females (mean $\pm \mathrm{SD}=247.49 \pm 90.05$ and $252.58 \pm 62.31$ respectively, $p=0.88$ ) (Figure 4 ).

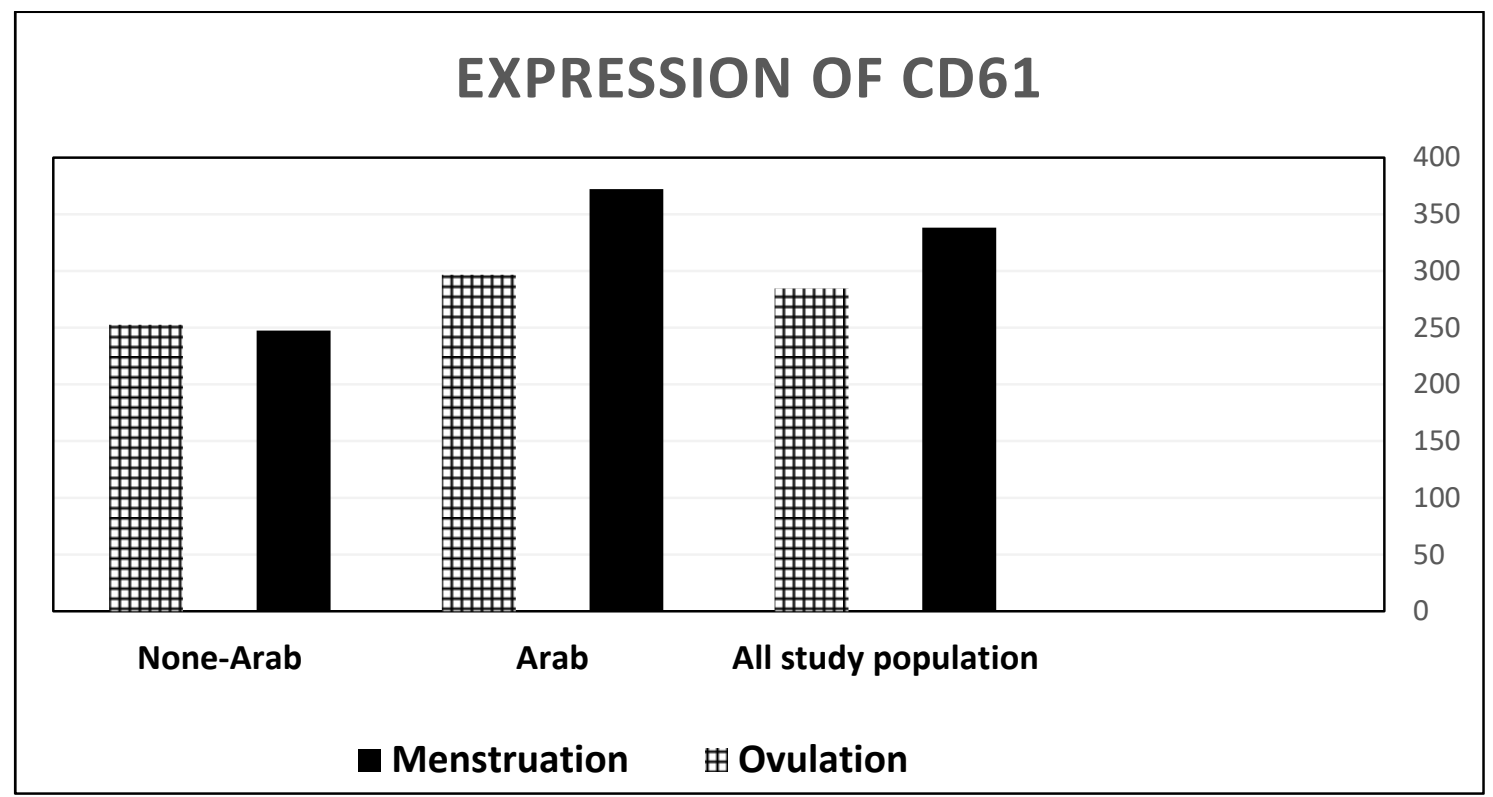

Figure 4. Expression of platelet CD61 during menstruation and ovulatory phase; in all study population $(p=0.09)$, Arab $(p=0.07)$ and none-Arab females $(p=0.88)$. The MFI values presented as mean+S.E.

\section{Discussion}

In this study we have addressed whether the expression of glycoprotein receptors of resting platelets was affected by estrogen levels during different phases of the menstrual cycle. Our data showed that no variation occurred in CD42b, CD41a, and CD61 expression among all study population. However, increase the surface expression level of CD49b during ovulatory phase was noted in none-Arab females. These findings suggest a role of estrogen in modulation of $\mathrm{CD} 49 \mathrm{~b}$. Generally, Normal menstruation starts with markedly decrease in progesterone and estrogen hormones where the cessation of menstrual bleeding is achieved by endometrial hemostasis through platelet aggregation, deposition of fibrin and thrombus formation (Davies \& Kadir, 2012). Estrogen was described to be strongly affecting platelet activity by activation of GPIIb/IIIa and platelet aggregation when induced by thrombin (Moro et al., 2005). The level of P-selectin reached the peak on day 14 of menstruation where the estrogen level is high during menstrual cycle phases. Platelet GPIIb/IIIa activity was reported to be increased in premenopausal women compared to men, which attributed to variation in estrogen and/or progestins levels (Faraday et al., 1997). Roshan, et al., 2005 stated that the expression of CD62P was increased in postmenopausal women, while the activation status of platelet was decreased in postmenopausal women assessed by a decrease level of P-selectin and GPIIb/IIIa expression (Aldrighi et al., 2005). Modulation of platelet function was determined by a decrease secretion of P-selectin without alteration of GPIIb/IIIa expression after estrogen replacement therapy (ERT) in postmenopausal women (Nakano et al., 2002). It was reported that ERT regulate GPVI expression but did not affect the level of GPIb or GPIIb/IIIa (Leng et al., 2005). Moreover, Williams, et al., 2005 stated that long-term ERT did not cause alteration in platelet activation that assessed by determination of the activation and aggregation markers P-selectin. Platelets were described to have a critical role in thrombosis in postmenopausal women (Aldrighi et al., 2005). The estrogen replacement therapy (ERT) modulates platelet function by decreasing $\mathrm{Ca}^{2+}$ influx and increasing production of $c$-AMP and reducing P-selectin level (Leng et al., 2005). The same report demonstrated that there was no significant change in expression level of GPIIb/IIIa after short term ERT. The level of GPIIb/IIIa in activated platelets by thrombin showed no differences between pregnant 
and non-pregnant women (Williams et al., 2005). The increased expression of resting platelet CD63 and activated platelet CD61, CD62P and CD63 in preeclampsia and normotensive pregnant women when compared to non-pregnant women (Sheu et al., 2002). The effect of ERT on platelet function was found to be dependent on the agonist hormones formulation and mode of delivery (Williams et al., 2005). Furthermore, the platelet physiological activity was affected by many factors including gender, race, diet and test system used (Holthe et al., 2004). The presence of significant difference in GP49b in the current study may have several explanations such as; A previous literature has not reliably found differences in platelet receptor expression between pregnant and nonpregnant or in response to short term estrogen and progesterone, But some studies confirmed that estrogen secreted by the growing ovarian follicles may causes prolonged vasoconstriction enabling the formation of a clot over the denuded endometrial vessels (Edman C. D., 1983; Reed \& Carr, 2018) besides the variation in the expression levels of GPIa/IIb between healthy individuals (Miller et al., 2014) and the density of GPIa/IIb vary 3to 4-fold and the differences in the activity and antigenicity of platelet GPIa/IIb may result from polymorphism(s) in $\alpha 2 \beta 1$ gene as described in previous studies (Curtis \& McFarland et al., 2014; Kunicki et al., 1993; Best et al., 2003). Therefore, integrin gene polymorphism, numbers of subjects and the short time scales relative to platelet turnover should be taken into consideration for suggested future studies to determine of the exact effects of this expression of platelet glycoprotein receptor for protection against hemorrhage, minimizing the risk of thromboembolism and recurrent spontaneous abortion in pregnant women.

\section{Conclusion}

In conclusion, The $\mathrm{CD} 49 \mathrm{~b}$ glycoprotein receptor was the commonly expression on the surface of platelet during menstruation and ovulatory phase of menstrual cycle in none-Arab compared to Arab reproductive age women in turn extended platelet activity in conjunction with interaction to the vascular wall consequences in elevated thrombus formation. The estrogen hormone determination and the appropriate time for sample collection for diagnosis of bleeding disorders due to platelet dysfunction might help in the designing a safe strategy of HRT. The conclusions derived from this study are limited. The need of greater understanding of the complex physiology and pharmacogenetic effects of sex hormones and their receptors on hemostasis is important for prevention of bleeding and thrombosis, for the management of abnormal uterine bleeding and to determine the benefit and which patient at risk of using hormone therapy. This can be achieved by conducting a larger controlled interventional study to investigate the effect of other sex hormones (progesterone, follicular stimulating hormone (FSH) and luteinizing hormone (LH) on platelet function and platelet glycoprotein receptors expression gene polymorphisms to cyclic versus non-cyclic shifts in expression for future large subject studies.

\section{Acknowledgements}

We thank Mr. Chitta Babo who helped throughout the flowcytometry work and Prof. Suliman Bah who guide in statistical analysis. We gratefully acknowledge the Imam Abdulrahman Bin Faisal University, laboratories of King Fahad Hospital of University and Institute for Research and Medical Consultations (IRMC).

\section{Funding}

This work was financially supported by the Deanship of Scientific Research in imam Abdulrahman Bin Faisal University, Dammam, Kingdom of Saudi Arabia (Grant number P2014002).

\section{Competing Interests Statement}

The authors declare that there are no competing or potential conflicts of interest.

\section{References}

Aldrighi, J. M., Oliveira, R. L., D'Amico, E., Rocha, T., Gebara, O. E., Rosano, G. M., \& Ramires, J. A. (2005). Platelet activation status decreases after menopause. Gynecological endocrinology. The Official Journal of the International Society of Gynecological Endocrinology, 20(5), 249-57. https://doi.org/10.1080/09513590500097549

Best, D., Senis, Y. A., Jarvis, G. E., Eagleton, H. J., Roberts, D. J., Saito, T., ... Watson, S. P. (2003). GPVI levels in platelets: Relationship to platelet function at high shear. Blood, 102(8), 2811-2818. https://doi.org/10.1182/blood-2003-01-0231

Chen, L. Y., \& Mehta, J. L. (1996). Further evidence of the presence of constitutive and inducible nitric oxide synthase isoforms in human platelets. $J$ Cardiovasc Pharmacol, $27,154$. https://doi.org/10.1097/00005344-199601000-00024

Curtis, B. R., \& McFarland, J. G. (2014). Human platelet antigens. Vox sanguinis, 106(2), 93-102. https://doi.org/10.1111/vox.12085 
Davies, J., \& Kadir R. A. (2019). Endometrial haemostasis and menstruation. Reviews in endocrine \& metabolic disorders, 13, 289-299. https://doi.org/10.1007/s11154-012-9226-4

Edman, C. D. (1983). The effects of steroids on the endometrium. Semin Reprod Endocrinol, 1(3), 179. https://doi.org/10.1055/s-2008-1067953

Faraday, N., Goldschmidt-Clermont, P. J., \& Bray, P. F. (1997). Gender differences in platelet GPIIb-IIIa activation. Thromb Haemost, 77(4), 748-754. https://doi.org/10.1055/s-0038-1656045

Feuring, M., Christ, M., Roell, A., Schueller, P., Losel, R., Dempfle, C. E., Schultz, A., \& Wehling, M. (2002). Alterations in platelet function during the ovarian cycle. Blood coagulation \& fibrinolysis: An international Journal In Haemostasis And Thrombosis, 13(5), 443-7. https://doi.org/10.1097/00001721-200207000-00009

Gopal, K., Nauder, F., Michele, L. K., Vinod, V., Everlie, B., Stephen, J. N., \& Paul, F. (2000). Human megakaryocytes and platelets contain the estrogen receptor $\beta$ and androgen receptor (AR): Testosterone regulates AR expression. Blood, 95, 2289-2296.

Holthe, M. R., Staff, A. C., Berge, L. N., \& Lyberg, T. (2004). Different levels of platelet activation in preeclamptic, normotensive pregnant, and nonpregnant women. American journal of obstetrics and gynecology, 190(4), 1128-34. https://doi.org/10.1016/j.ajog.2003.10.699

Jones, S. B., Bylund, D. B., Rieser, C. A., Shekim, W. O., Byer, J. A., \& Carr, G. W. (1983). a2-Adrenergic receptor binding in human platelets: Alterations during the menstrual cycle. Clin Pharmacol Ther, 34, 90. https://doi.org/10.1038/clpt.1983.135

Kiefel, V., Vicariot, M., Giovangrandi, Y., Kroll, H., Bohringer, M., Greinacher, A., ... \& Mueller-Eckhardt, C. (1995). Alloimmunization against Iy, a low-frequency antigen on platelet glycoprotein Ib/IX as a cause of severe neonatal alloimmune thrombocytopenic purpura. Vox Sang, 69(3), 250-4. https://doi.org/10.1159/000462848

Kunicki, T. J., Orchekowski, R., Annis, D., \& Honda, Y. (1993). Variability of integrin alpha 2 beta 1 activity on human platelets. Blood, 82(9), 2693.

Leng, X.-H., Zhang, W., Nieswandt, B., \& Bray, P. F. (2005). Effects of estrogen replacement therapies on mouse platelet function and glycoprotein VI levels. Circulation research, 97(5), 415-417. https://doi.org/10.1161/01.RES.0000181025.43762.cf

Malipatil, B. S., \& Patil, S. (22013). Hematological modulation in different phases of menstrual cycle. IJBR, 4(2), 6. https://doi.org/10.7439/ijbr.v4i2.932

Miller, C. H., Rice, A. S., Garrett, K., \& Stein, S. F. (2014). Gender, race and diet affect platelet function tests in normal subjects, contributing to a high rate of abnormal results. Br J Haematol, 165(6), 842-53. https://doi.org/10.1111/bjh.12827

Moro L., Reineri, S., Piranda, D., Pietrapiana, D., Lova, P., Bertoni, A., ... Sinigaglia, F. (2005). Nongenomic effects of 17beta-estradiol in human platelets: potentiation of thrombin-induced aggregation through estrogen receptor beta and Src kinase. Blood, 105(1), 115-21. https://doi.org/10.1182/blood-2003-11-3840

Nakano, Y., Oshima, T., Ozono, R., Ueda, A., Oue, Y., Matsuura, H., ... Kambe, M. (2002). Estrogen replacement suppresses function of thrombin stimulated platelets by inhibiting $\mathrm{Ca}^{2+}$ influx and raising cyclic adenosine monophosphate. Cardiovascular research, 53(3), 634-641. https://doi.org/10.1016/S0008-6363(01)00410-2

Nir, M., Yariv, Y., Tal, B., Eran, A., Andreas, C., \& Marek, G. (2010). The effect of menstrual cycle on platelet aggregation in reproductive-age women. Platelets, 21(5). https://doi.org/10.3109/09537101003770595

Reed, B. G., \& Carr, B. R. (2018). The Normal Menstrual Cycle and the Control of Ovulation. In L. J. De Groot, G. Chrousos, K. Dungan, et al. (Eds.). Endotext [Internet]. South Dartmouth (MA): MDText.com, Inc. Retrieved Aug 5, 2018, from https://www.ncbi.nlm.nih.gov/books/NBK279054/

Roshan, T. M., Normah, J., Rehman, A., \& Naing, L. (2005). Effect of menopause on platelet activation markers determined by flow cytometry. American Journal of Hematology, 80(4), 257-261. https://doi.org/10.1002/ajh.20472

Rosin, C., Brunner, M., Lehr, S., Quehenberger, P., \& Panzer, S. (2006). The formation of platelet-leukocyte aggregates varies during the menstrual cycle. Platelets, 61-6(1), 17. https://doi.org/10.1080/09537100500227021

Sheu, J. R., Hsiao, G., Shen, M. Y., Lin, W. Y., \& Tzeng, C. R. (2002). The hyperaggregability of platelets from 
normal pregnancy is mediated through thromboxane A2 and cyclic AMP pathways. Clinical and laboratory haematology, 24(2), 121-121. https://doi.org/10.1046/j.1365-2257.2002.00430.x

Tarantino, M. D., Kunicki, T. J., \& Nugent, D. J. (1994). The estrogen receptor is present in human megakaryocytes. Ann N Y Acad Sci., 714, 293. https://doi.org/10.1111/j.1749-6632.1994.tb12059.x

Williams, M. S., Vaidya, D., Kickler, T., \& Ouyang, P. (2005). Long-term hormone replacement therapy does not cause increased platelet activation. American Heart Journal, 150(3), 434-438. https://doi.org/10.1016/j.ahj.2004.10.028

\section{Copyrights}

Copyright for this article is retained by the author(s), with first publication rights granted to the journal.

This is an open-access article distributed under the terms and conditions of the Creative Commons Attribution license (http://creativecommons.org/licenses/by/4.0/). 